\title{
Management Research Of Employee Engagement Based On The Psychological Contract
}

\author{
Lan Zhu \\ School of Hohai University, Nanjing, 210000, China. \\ zhulan009208@163.com
}

Keywords: engagement, psychological contract, role expectancy

\begin{abstract}
Employee engagement is one of the recent concepts in organizational behavior,which is an important topic academically and practically.Improving emplyee Engagement is regarded as the central part of enterprise's strategies. The enterprise not Only should pay attention on the employees' loyalty to the organization,but also the Loyalty to the job needed to be noticed.There are three aspects of the employee engagement,energy,devotion,attention.All these are defined by the Psychological contract containing the role expectancy as the major part.According to psychological contract and engagement,this paper analyzes the role expectancy as intermediate variable and found the model of the mutual effect based on psychological contract and employee engagement with the aim to explore the ways for increasing the emplyoee engagement.
\end{abstract}

\section{Introduction}

China Human Resources Development Network on China enterprise employee engagement index 2005 annual report showed that level of dedication in 4.0\%. 2010 Chinese professional degree survey, 21 percent of workers is a dedicated, Towers Perrin 2007 survey, only 16\% of Chinese employees showed higher engagement, 33\% showed low engagement. Whether it is a consulting company survey or social status, employee engagement is an indisputable fact, which makes us have to pay attention to the problem of employee engagement. A series of research shows that employee engagement and organizational expectations of the results is related (business performance, employee turnover, retention rate and productivity).This paper based on the theory of psychological contract and employee engagement, builds a bridge of the psychological contract from different kinds and engagement, establishing the interaction mechanism model, which will provide a reference for theoretical research and management practice.

\section{Psychological contract}

The concept of psychological contract. The term of psychological contract is introduced into the management field in early 1960s. ${ }^{[1]}$ It is emphasized on the relationship between employees and organizations. In addition to the formal employment contract, there are implicit, informal and non publicly stated expectations. They are also the important factors that determine the behavior of employees:

The first stage, introduced the concept of the late phase (the 20th century, the 1960s to the early 1980s). Organizational psychologist Argyris in 1960 in the book < understanding organizational behavior > was first one putting forward the "psychological contract", he used "psychological work contract" to describe the relationship between the employees and the foreman in a factory, Argyris pioneered the research of psychological contract, but he did not make an exact definition of the concept of psychological.1962.Levinson described the psychological contract as "no written contract"'in the case study of a public institution.The second stage: the concept development stage (end of 1980s, 1994). ${ }^{[2]}$ In the early period of the concept definition, the psychological contract is considered to exist in the 20 century 80's in the Rousseau century, which is the subjective understanding of the relationship between the two parties. Third stage: the empirical research stage (after 1994). With the deepening of research, more and more researchers used quantitative methods to 
explore the psychological contract. At present, the research mainly along the psychological contract content and dynamic development process. The understanding of the psychological contract here is a kind of generalized psychological contract. There is an unwritten agreement between employers and employees, the individual will have a great impact on the individual and organization and work.

The type of psychological contract.In addition to the "transaction relationship" dimension, Rousseau (1995) according the employer's contract duration and performance requirements explicitly or not to make combination, the psychological contract is divided into transactional (short-term and performance requirement is clear), relational (long-term and performance requirements are not clear), balanced (long-term and performance requirements are clear) and variable (short-term performance requirements are not clear) 4 types.

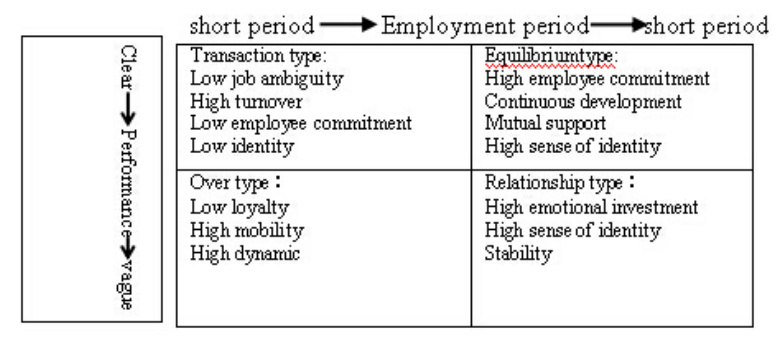

Figure 1 the type of psychological contract

\section{Employee engagement}

The concept of employee engagement.Kahn first proposed the concept of employee engagement in 1990, followed by domestic and foreign scholars to study the concept and structure, which, Kahn (1990) defined it as the individual in the promotion and other related work tasks in the use and expression of the best condition, the structural dimensions included physical, cognitive and emotional.Recently,domestic scholars have carried out the relevant research ,Such as Xuemei Liu (2003) defined it as the dedication of the staff in the emotional and behavioral aspects of a commitment. ${ }^{[3]}$ Lai Tan Fang and Kan Shi etc(2010) defined the employee engagement as involvement degree of performance,when employees combined themselves with work roles,also,to work, the team and the organization .

Dimension of employee engagement.After the engagement was put forward,the scholars explored the different questionnaire based on the various engagement theory.But the most authoritative is Gallup workplace survey (GallupWorkplaceAudit GWA) (0.85). It is mainly through the working environment for staff and management system to reflect the employee engagement conditions, including 12 questions, has been more widely used in the field of practice ${ }^{[4]}$.

\section{Psychological contract and employee engagement.}

The interaction mechanism theory of psychological contract and employee engagement. The psychological contract is the mutual expectation of both sides, that is, the expectation of employees and employees. In fact, it is the psychological contract that defines the behavior of each role, and it is easier to express the employee's emotion.As more and more enterprise employees began to not only to be loyal to the organization, but also to the occupation.For the fit between individual and organization,Organization will create fair, ethical work environment with certain expectations and incentive,the individual use the resources provided by the organization and devote their energy and skills to the work with high expectation and returns. ${ }^{[5]}$ For the fit between individual and work:as for the loyalty to the work,making the employees more willing to devote their energy to the work,which is not required by the organization clearly.In other words, that is the fit between the work and employee.The achievement sense and the realization of the value of the individual is the primary reason for the occupation.Of course,with the individual to the work investment increased,work will give the individual bring unexpected return, may be beyond their expectations.

According to the content of psychological contract, from the perspective of employee's role, the 
psychological contract can be divided into individual and organization. It is helpful for the successful transformation of the organization, the positive development of the employment relationship, and reduce employee turnover.At the same time, the construction of a good psychological contract can also correspond to improve the employee engagement.

The interaction mechanism model of psychological contract and employee engagement. From the definition of employee engagement can be seen,Employee engagement is the result of the employee's energy input to work, and hope to have a good effect, which is influenced by the role of the organization.From the influence factors of employee engagement,On the one hand, the work resources ( the training guidance, motivation, etc. provided by organization) and personal resources (positive self perception) : the fit of the individual and the work will have an impact on the employee engagement.On the other hand, the value of employees and organizational values is consistency or not will also affect the employee engagement.Some researchers have pointed out the contents of employee engagement, based on these 6 questions: "what can I do for the enterprise," "what is my department, what's my job is what I do", "people care about me or not".Based on the 6 problems, this paper classifies them into two levels: Organization engagement, job engagement, and psychological contract, which is based on the psychological contract.Taking the role expectation as the starting point, the mechanism model of the two is established.

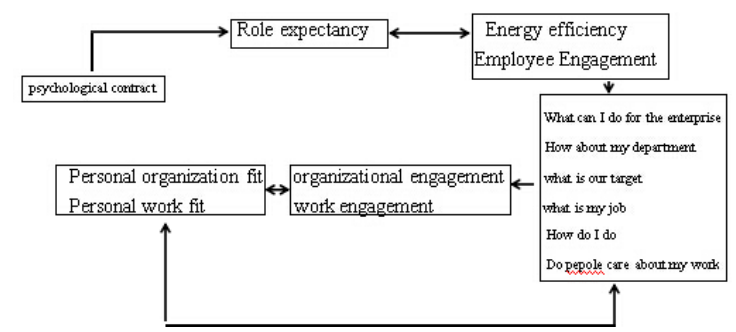

Figure 2. Psychological contract and employee engagement mechanism model

\section{The Management enlightenment of employee engagement based on psychological contract}

The personal--work fit.In the work, convey the positive information to the employees. Research shows that the more positive information from the outside world, the more confidence that the staff have on the job, the work will be the greater .In the process of giving information to employees, managers will be expected to pass role expectation information to employees, so that employees and work can fit better.Only after they have a good understanding of their role expectation , their potential will be motivated, such as enthusiasm, spirit of cooperation, initiative and so on to devote their energy,dedication and attention to the work. ${ }^{[6]}$ In the daily management work, the manager should try to express the positive expectation to the employees.Input the positive information to employees through various ways, so that employees understand what company's employees expect from their role.Although the information is subtle,employees feel the positive expectations of managers, to a certain extent, can reflect the positive effect of the work.

Understand the potential needs of employees in the work.The role expectation between the manager and employee is not presented by words but more in the fit in psychology.Therefore, managers should pay more attention to the inner needs of the staff.To achieve this, the organization's management should be more empathy, for the needs of the staff spirit, and consciously give the main role expectation in the collective consciousness, so that employees can fully display their own life value and labor value, in pursuit of the goal of achieving the organization's objectives.In fact, people's understanding of individual ability is confirmed by the ability of the individual to work and study.Every one has the ability to be known more or less.If he could give him a different level of encouragement, he could emit some new energy.The more capacity of an individual to display,he will be confirmed more, The more expectations the manager gives, the higher the degree of personal and work fit.Means that the individual's stronger ability to adapt to the work and lighter work pressure, so as to encourage employees engagement. 
The person - organization fit.Creating a working atmosphere in the organization, the manager should establish the trust between employees and organizations.The psychological contract follows the principle of social exchange, and one party may have to pay and get the other party's return in the future, and the way of return is not sure, So this requires the mutual trust between the two parties.Organizations want to have a high degree of engagement,you have to get the trust of employees, so that they are willing to dedicate into the work.In the initial establishment of the psychological contract with the staff, the organization should pay attention to the build of the trust of employees in the recruitment interview.Enterprises should make employees have a real understanding of the organization,the favorable and unfavorable aspects should be truthful, avoiding making commitments that can not be achieved to build trust.In addition, one scholar's research shows that employees' organizational justice and trust has a significant relationship, in particular, the program fair, so the organization must allow employees to feel a kind of fair management mechanism, making employees can feel that through a fair and transparent process.

Developing consistent values.The release of employee energy is influenced by the value,developing the value is important for the employee's engagement. When the individual values are different with the organization,they will find out what they think is not consistent with what they have to do,the role expectation of organization is not agree with themselves'. That is the violation of psychological contract,resulting in the decline of employee engagement.

Communication in psychological contract level.Psychological contract is a dynamic process, which needs to continue to revise according to the expectations of the two sides, so the daily communication is more essential.At this point, the management of Japan is very much in place.For example, many managers will take time to communicating with the different departments of the unit face to face, even if only to talk about trivial things, but the psychological has been given a solid weight.In this process, the manager also obtained the valuable information, the employee's role expectation in the organization, also has the right to change management mechanism.Timely communication can find the problem to re-establish the staff's trust of the organization and bridge the rift of possible psychological contract.

\section{Summary}

Employee engagement is related to the trust and loyalty of employees, which is closely linked with the results of the organization's expectations.It is an important problem in management theory and practice, how to improve the employee engagement has been placed in the enterprise's strategic core position. This paper starts from the perspective of psychological contract theory and employee engagement, chooses the role expectation theory as the intermediate variable,establishing the interaction mechanism model of psychological contract and employee engagement,and the research on the employee engagement is deepened.Employee engagement includes physical input, emotional expression, attention and investment.Among them, the emotional expression of employees is more likely to work in the performance, if the individual self input and organizational expectations are not consistent, the employee engagement will be reduced, it is the psychological contract to define the behavior of each role.According to the content of the engagement, it is divided into the organization and work engagement.Similarly, in the psychological contract, the individual and the organization's fit, the individual and the work fit through the role expectation of the intermediate variable influence the employee engagement.This model also has some practical significance, On the one hand, the analysis of the work itself, on the other hand, pay attention to the consistency of values.From the role expectation, managers can improve the employee engagement from psychological contract level.Finally, some deficiencies exist in this article, first of all, from the literature, not exhausted all the current literature, but refers to the part of the literature.Secondly, analysis method is not so fine, the lack of support, more practice not exhaustive.Of course, this is also a issue worthy of study and practice of long-term exploration and practice. 


\section{References}

[1] Macey W H,Schneider B. The Meaning of Employee Engagement[J].Industrial and Organizational Psychology,1998.

[2] Delaney J T, Huselid M A. The Impact of Human Resource Management Practices on Perceptions of Organizational Performance [J]. Academy of Management Journal,1996.

[3] Hakanen J J,Perhoniemi R,Toppinen-Tanner S:from Job Resources toWork Engagement, Personal Initiative and Work-Unit Innovativeness [J].Journal of Vocational Behavior,2008.

[4] MillsC.F.Employee Engagement in the Wireless Industry:AValidityStudy[D].Capella University, 2005.

[5] KahnWA.PsychologicalConditions of Personal Engagement at Work[J].Academy of Management Journal,1990.

[6] Laitan fang,kan Shi,fanghua zhang.A review of research on employee engagement[J]. Management Review,2010. 